\title{
Age-Related Changes in Twitch Properties of Plantar Flexor Muscles in Prepubertal Children
}

\author{
JEAN-FRANCOIS GROSSET, ISABELLE MORA, DANIEL LAMBERTZ, AND CHANTAL PEROT \\ Département de Génie Biologique [J.-F.G., D.L., C.P.], CNRS UMR-6600, Université de Technologie, \\ Compiègne cedex, France and EA 3300 [I.M.], APS et Conduites Motrices, Université de Picardie Jules \\ Verne, F-80025 Amiens, France
}

\begin{tabular}{|c|c|}
\hline \multicolumn{2}{|c|}{ ABSTRACT } \\
\hline $\begin{array}{l}\text { The twitch of the triceps surae muscle (TS), which charac- } \\
\text { terizes the contractile properties independently of volition, differs } \\
\text { in amplitude, but not in time course, when evoked in pre or } \\
\text { postpubertal children. The aim of the present study was to } \\
\text { compare the TS twitch contractile properties in prepubertal chil- } \\
\text { dren ( } 7 \text { to } 11 \text { y). M-wave and twitch were recorded at rest by } \\
\text { supramaximal electrical stimulations of the posterior tibial nerve. } \\
\text { Twitches were characterized by peak torque (Pt), contraction } \\
\text { time (CT), half relaxation time (HRT), and rate of torque devel- } \\
\text { opment (dPt/dt). Electromechanical delay (EMD) was quantified } \\
\text { with regard to the TS M-wave onset. Pt values increased signif- } \\
\text { icantly with the age of the prepubertal children but remained } \\
\text { lower than that for adult subjects. CT and HRT values did not } \\
\text { change with age. Thus, dPt/dt increased significantly between the } \\
7 \text {-year-old and the } 11 \text {-year-old children but remained signifi- } \\
\text { cantly lower than that for adults. Despite EMD values decreased } \\
\text { with age, they remained significantly higher than those of adult } \\
\text { subjects. These results confirmed the link between growth pro- }\end{array}$ & $\begin{array}{l}\text { cesses and the increase in twitch torque for prepubertal children } \\
\text { within a limited range of age. However, the time-course charac- } \\
\text { teristics were not affected by age. The increase in } \mathrm{dPt} / \mathrm{dt} \text { and the } \\
\text { decrease in the EMD could be used as indirect indicators of } \\
\text { changes in contractile kinetics and in musculo-tendinous stiffness } \\
\text { with the age of the prepubertal children. The age-related rela- } \\
\text { tionships established by this study will serve as reference values } \\
\text { for clinical testing of the TS performances in relation to muscle } \\
\text { disease or disuse. (Pediatr Res } \mathbf{5 8 : ~ 9 6 6 - 9 7 0 , ~ 2 0 0 5 ) ~} \\
\text { CT, contraction time } \\
\text { dPt/dt, rate of torque development } \\
\text { EMD, electromechanical delay } \\
\text { EMG, electromyogram } \\
\text { HRT, half relaxation time } \\
\text { Pt, peak torque } \\
\text { TS, triceps surae }\end{array}$ \\
\hline
\end{tabular}

It is now well-established that during growth, muscles become stronger (1-4) and this increase in strength is associated with changes in body and muscle sizes $(2,5,6)$.

Electrical stimulation techniques, to evoke twitches, can be used to quantify contractile properties independently of volition and skill of the subject. This was performed to compare contractile properties of skeletal muscles between prepubertal and postpubertal children $(1,2)$ or between children (prepubertal and postpubertal) and adult subjects $(4,7)$. It has been shown that twitch force increased with age (1-4) and that this increase was related to the increase in muscle size (2). Furthermore, no significant difference in the time course of the twitch (contraction time and half relaxation time) was reported between prepubertal and

Received September 30, 2004; accepted March 9, 2005.

Correspondence: Chantal Pérot, Ph.D., Université de Technologie de Compiègne, Département Génie Biologique CNRS UMR-6600, F-60205 Compiègne cedex, France; e-mail: chantal.perot@utc.fr.

This study was supported by grants from the Centre National d'Etudes Spatiales (CNES) and the Pôle GBM Périnatalité-Enfance de la Région Picardie.

DOI: 10.1203/01.PDR.0000181375.61935.7D postpubertal children (1-4), which suggests that the fiber-type composition of the muscles was already adult-like.

In the present study, we analyze contractile properties during prepubertal growth (between 7 and $11 \mathrm{y}$ ), not only by the measure of the twitch peak torque and the time-course characteristics of the twitch but also by the quantification of the rate of torque development and of the electromechanical delay.

In humans, the rate of torque development has been used to assess changes in muscle contractile kinetics with immobilization (8), electrostimulation training (9), or aging (10).

The electromechanical delay (EMD) measured in vivo informs principally about the force transmission through more or less compliant elastic elements rather than about the mechanisms of excitation-contraction coupling (11). EMD values were found to depend on the gender of adult subjects (12), on the initial muscle length at which they are measured (13), and on the state of ankle stability (14). In each case, the differences in EMD values have been interpreted in terms of changes in musculo-tendinous stiffness.

The analyses of twitch contraction may represent a simple indicator to assess changes in contractile and elastic properties 
of muscle with the age of prepubertal children. The data collected in many children allow us to establish reference relationships useful later to evaluate triceps surae deficit caused by disease or disuse.

\section{METHODS}

Subjects. Forty-eight healthy 7- to 11-year-old prepubertal children (30 girls and 18 boys) were tested at the University Hospital Center in Amiens (Picardie, France). The medical staff determined the pubertal status of each child. Based on no pubic hair, no breast development, and no apparent changes in the voice and skin, all children were classified as prepubescent. Anthropometric measurements included calf circumference, body mass, and height. Additional experiments were performed on nine male college students who constituted an adult target group for the same parameters $(21.0 \pm 2.3 \mathrm{y})$. Age and anthropometric characteristics are given in Table 1.

Written informed consent was given by the college students and, for the children, by the legal guardians who were always present during testing, fully advised of the procedures, and free to withdraw their child from the experiment at any time. The committee of hygiene, safety, and ethics and the Consultative Committee of People Protection in Biomedical Research (CCPPRB) of the University approved the experimental protocol.

Ergometric device. The ankle ergometer used for this study has been described in detail by Tognella et al. (15), but was adapted to child's testing. Briefly the ergometer consisted of two main units: (1) a power unit that contained the actuator, its power supply unit, and its associated electronics; and (2) a driving unit controlled by a 486 PC-type computer equipped with a 12-bit analog/digital board. At the actuator, angular displacement was measured with an optical digital sensor (IVO) and torque was obtained using a strain-gauge torque transducer (FGP Instrumentation, CD 1050, 200 Nm). Custom driven software controlled all procedures.

Protocol. The subject was comfortably sat on an adjustable armchair with the left foot firmly maintained in a sport shoe fixed on the footplate of the

Table 1. Anthropometric characteristics of the healthy prepubertal children and adult groups

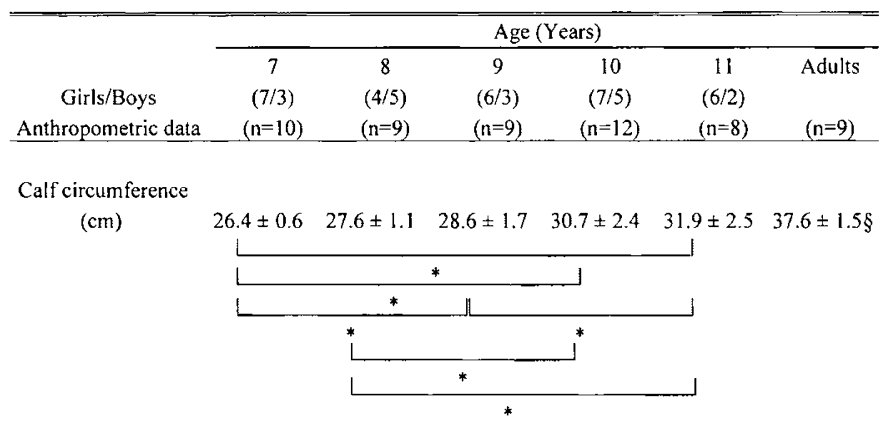

Height

$(\mathrm{cm})$

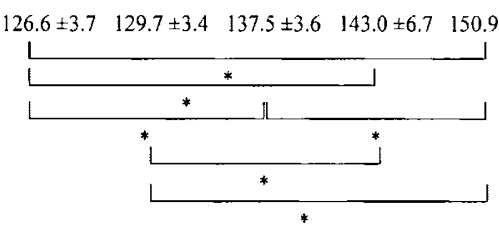

Body mass

$(\mathrm{kg})$

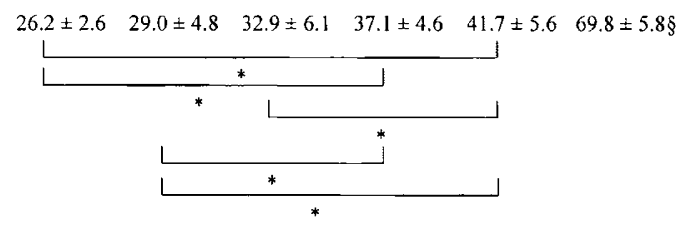

Girls and boys (respective numbers are given in front of the Table) have been distributed in five groups of age but, obviously, inside a group, the age may vary from several months. Data are represented as mean \pm SE. (*) denotes significant differences between the prepubertal children and $(\S)$ denotes significant differences between the adult subjects and each prepubertal child group from ANOVA $(p<0.05)$. actuator. The horizontal bi-malleolar axis coincided with the axis of rotation of the actuator. The knee was flexed to $120^{\circ}$ and the ankle to $90^{\circ}$.

Surface electromyograms (EMG) were detected on each part of the triceps surae muscle group (TS), i.e., the soleus (Sol), the gastrocnemius lateralis (GL), and the gastrocnemius medialis (GM) in bipolar mode using standard $\mathrm{Ag} / \mathrm{AgCl}$ surface electrodes (Beckman, $2 \mathrm{~mm}$ in diameter), spaced $15 \mathrm{~mm}$ center to center. As classically performed when studying M-wave, surface electrodes were preferred to wire electrodes due to their noninvasive character, very important for testing on healthy children. To reduce the electrode impedance to below $5 \mathrm{k} \Omega$, the skin areas over the electrode application sites were rubbed with an abrasive skin cleaning paste and cleaned with an alcohol pad. Electrolytic gel was used with all surface electrodes for good electroconductive coupling. The surface electrodes were placed over the belly of each gastrocnemius muscle and $2 \mathrm{~cm}$ below the insertion of the gastrocnemii on the Achilles tendon for the soleus. The ground electrode (silver plate of $4 \times 5 \mathrm{~cm}$ covered with electrolytic gel) was placed over the tibia. EMG signals were addressed to isolated differential amplifiers (GOULD 6600; gains between 1000 and 5000) and band-pass-filtered (1 Hz to $1 \mathrm{kHz})$. EMG and mechanical signals were then sent to the analog/digital board (sampling frequency of 15 $\mathrm{kHz}$ ) and stored for further signal processing.

The supramaximal electrical stimulation of the posterior tibial nerve was elicited at rest with the cathode located in the poplitea fossa and the anode placed on the thigh, proximal to the patella. Elastic bandages were used to keep the electrodes in place and to ensure good electrode contact. Single electrical pulses (1 ms in duration) were delivered from an isolated constant current stimulator (DS7A, Digitimer) at intensity 20\% higher than the intensity giving the maximal M-wave on each part of the triceps surae. Five supramaximal stimulations were elicited and the corresponding M-waves and twitches were stored and later averaged.

Measurements and data processing. Data processing was done on the signals obtained after the five trials were averaged. The mean EMG signals of the Sol, GL, and GM were rectified and summed up to get TS $\mathrm{M}_{\max }$ response. Mean amplitude of TS $\mathrm{M}_{\max }$ response (TSM $\overline{\max }_{\text {max }}$ ) was defined as the ratio between TS $\mathrm{M}_{\max }$ area and TS $\mathrm{M}_{\max }$ duration. The analysis of mean amplitude was preferred to that of peak-to-peak amplitude because of the polyphasic responses often recorded on the gastrocnemii muscles (16). As shown in Fig. $1 A$, different parameters were calculated on the mean mechanograms, namely: (i) the electromechanical delay (EMD, ms) defined as the delay between the onset of $\mathrm{TS} \mathrm{M}_{\max }$ response and the onset of the torque development; (ii) the peak torque $(\mathrm{Pt}, \mathrm{Nm})$; (iii) the contraction time $(\mathrm{CT}, \mathrm{ms})$; (iv) the half relaxation time (HRT, ms); and (v) the rate of torque development $(\mathrm{dPt} / \mathrm{dt}$, $\mathrm{Nm} \cdot \mathrm{s}^{-1}$ ). Pt and HRT were automatically calculated thanks to a specific software. To calculate EMD, CT, and $\mathrm{dPt} / \mathrm{dt}$, the experimenter had to point out the TS M-wave latency, the onset of the torque development and two points of the linear ascending phase of the torque development (see Fig. 1A). This manual pointing to determine the maximal slope of the ascending phase of the twitch torque (defined as $\mathrm{dPt} / \mathrm{dt}$ ) was preferred to the determination of $\mathrm{dPt} / \mathrm{dt}$

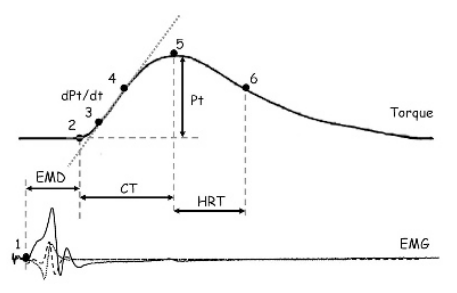

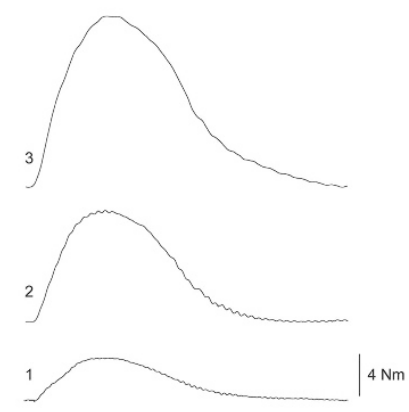

Figure 1. In $A$, EMG traces of the three parts of the triceps surae (soleus muscle in thick line; gastrocnemius lateralis in small dotted line, and gastrocnemius medialis in large dotted line) and twitch torque as a function of time. The different parameters analyzed are defined on these traces. The points 1, 2, 3 , and 4 were chosen manually, whereas points 5 and 6 were automatically calculated. These points allowed the calculation of the electromechanical delay (EMD), the rate of torque development (dPt/dt), the contraction time (CT), peak torque (Pt), and half relaxation time (HRT). In $B$, typical examples of the twitch torque, as a function of time (ms), for a 7-year-old child (1), an 11 -year-old child (2), and an adult subject (3). For each subject, the twitch torque was the mean of the tracings recorded in response to five supramaximal electrical stimulations applied to the posterior tibial nerve. 
by the derivative of the torque traces, because of a small level of electromagnetic noise that contaminated the torque signals and impeded the calculation of correct derivative traces.

Statistics. Linear regression analyses were used to attest age-related changes of the different parameters. Two-way analyses of variance (ANOVA) were used to analyze the effect of age and gender of the prepubertal children. In the case when no influence of gender was found, one-way ANOVA was used to attest age effects inside the prepubertal children groups and between the children groups and the adult group. When ANOVA indicated significant differences, a post hoc Fisher test was used to determine which means were significantly different from which others. Values are represented as mean \pm SE. Differences were considered significant when $p$ was less than $0.05(p<$ $0.05)$.

\section{RESULTS}

First, it was verified that, for a given age, none of the measured parameters was influenced by the gender of the child. Because no gender-dependence of the parameters was statistically observed, data of girls and boys were pooled for each age-group of children.

Table 1 summarizes mean anthropometric data for all children and reveals that all measured parameters (calf circumference, height and body mass) increased significantly with the age of the prepubertal children. Whatever the age, prepubertal children presented always anthropometric data values significantly lower than that of adult subjects.

TS $\bar{M}_{\max }$ was not affected by the age of the children and did not differ from adult values.

Figure $1 B$ presents three typical examples of twitch torque of the plantar flexors as a function of time. This figure wellillustrates the age-related increase in Pt values and also indicates that despite the lower Pt values, CT values did not differ between the 7-year-old child, the 11-year-old child, and the adult subject. These individual data were confirmed by the analysis of mean values for the population.

As indicated in Fig. 2A, ANOVA analysis applied to $\mathrm{Pt}$ values revealed significant differences between the prepubertal age groups $(\mathrm{F}(4,43)=76.6, p<0.0001)$. Furthermore, $\mathrm{Pt}$ of prepubertal children was significantly related to age $(\mathrm{r}=0.79$, $n=48, p<0.05$ ), leading to an increase from $4.2 \pm 0.4 \mathrm{Nm}$ for the 7-year-old children to $9.7 \pm 1.0 \mathrm{Nm}$ for the 11 -year-old children. Figure $2 A$ also shows that $\mathrm{Pt}$ values of the adult subjects were significantly different with regard to prepubertal age groups $(\mathrm{F}(5,51)=76.6, p<0.0001)$. This correlation was still observed after $\mathrm{Pt}$ values were normalized with regard to calf circumference ( $\mathrm{r}=0.64, n=48, p<0.05)$ (Fig. $2 B$ ). Whatever the case, $\mathrm{Pt}$ values were significantly lower for the five age groups of children compared with the adult group ( $\mathrm{F}$ $(5,51)=25.9, p<0.0001)$.

As for CT and HRT, ANOVA analysis indicated no significant difference of these parameters between the different prepubertal age groups $(\mathrm{CT}: \mathrm{F}(4,43)=0.12, p=0.97$; HRT: $\mathrm{F}(4,43)=0.17, p=0.95)$ and between the children and the adult subjects $(\mathrm{CT}: \mathrm{F}(5,51)=0.11, p=0.98$; HRT: $\mathrm{F}(5,51)$ $=0.15, p=0.97)$. Regression analysis confirmed that mean CT (Fig. 3A) and HRT values (Fig. 3B) did not change with age and were already at adult values (CT: $\mathrm{r}=0.01, n=48, p>$ 0.05; HRT: $\mathrm{r}=0.10, n=48, p>0.05)$.

In Figure $4 A$, ANOVA analysis revealed significant differences in mean $\mathrm{dPt} / \mathrm{dt}$ between the prepubertal age groups $(\mathrm{F}$ (4, $43)=11.9, p<0.0001)$. The increase in $\mathrm{dPt} / \mathrm{dt}$ was signifi-
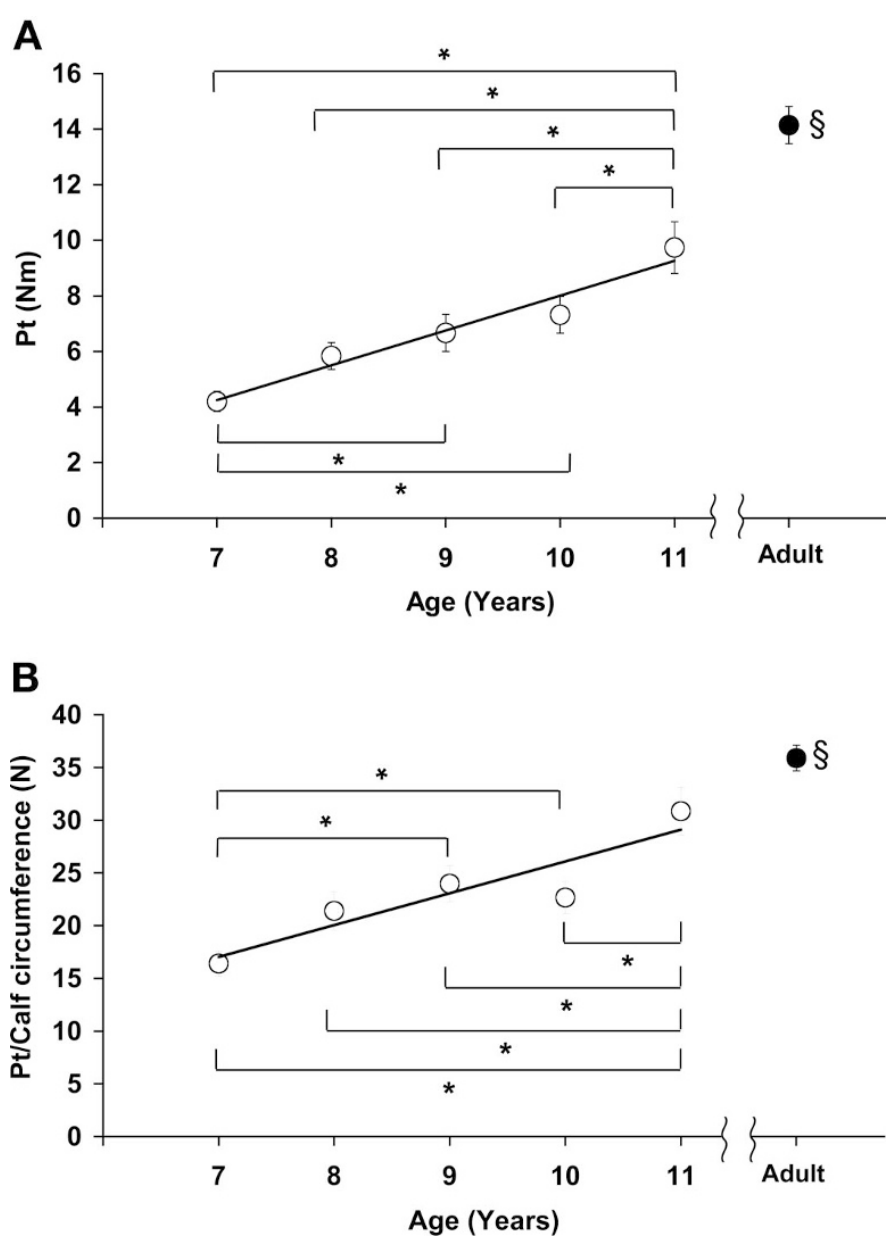

Figure 2. In $A$, relationship between twitch torque (Pt, $\mathrm{Nm}$ ) and age (years) for prepubertal children (O) and the adult subjects $(\bigcirc)$. In $B$, Pt values were expressed with regard to calf circumference $(\mathrm{N})$. * Significant differences between prepubertal children of different age. §Significant differences between the adult subjects and each prepubertal child group from ANOVA ( $n=48 ; p$ $<0.05)$. Data are represented as mean values $\pm \mathrm{SE}$.

cantly related to age $(\mathrm{r}=0.69, n=48, p<0.05)$ with values varying from $55.0 \pm 12.6 \mathrm{Nm} . \mathrm{s}^{-1}$ for the youngest children to $142.7 \pm 11.1 \mathrm{Nm} . \mathrm{s}^{-1}$ for the oldest ones. These values remained significantly lower compared with the adult target

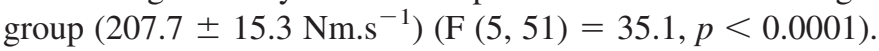

Figure $4 B$ shows that mean EMD values was the highest for 7-year-old children $(15.3 \pm 0.9 \mathrm{~ms})$ and then decreased to 13.8 $\pm 0.8 \mathrm{~ms}$ for the 11 -year-old children. Regression analysis also indicated that this decrease was significantly related to age $(\mathrm{r}=$ $0.31, n=48, p<0.05)$. However, no statistical differences were revealed by the ANOVA analysis $(\mathrm{F}(4,43)=0.75, p=$ 0.56). Nevertheless, EMD values were significantly shorter for adults than for prepubertal children whatever their age ( F (5, 51) $=3.54, p=0.008$ )

\section{DISCUSSION}

This study illustrates differences in the plantar flexor twitch contractile properties with the age of the prepubertal children, knowing that an evoked contraction provides an indication of changes in muscle properties independently of volition or alterations in the central recruitment of motor units. 

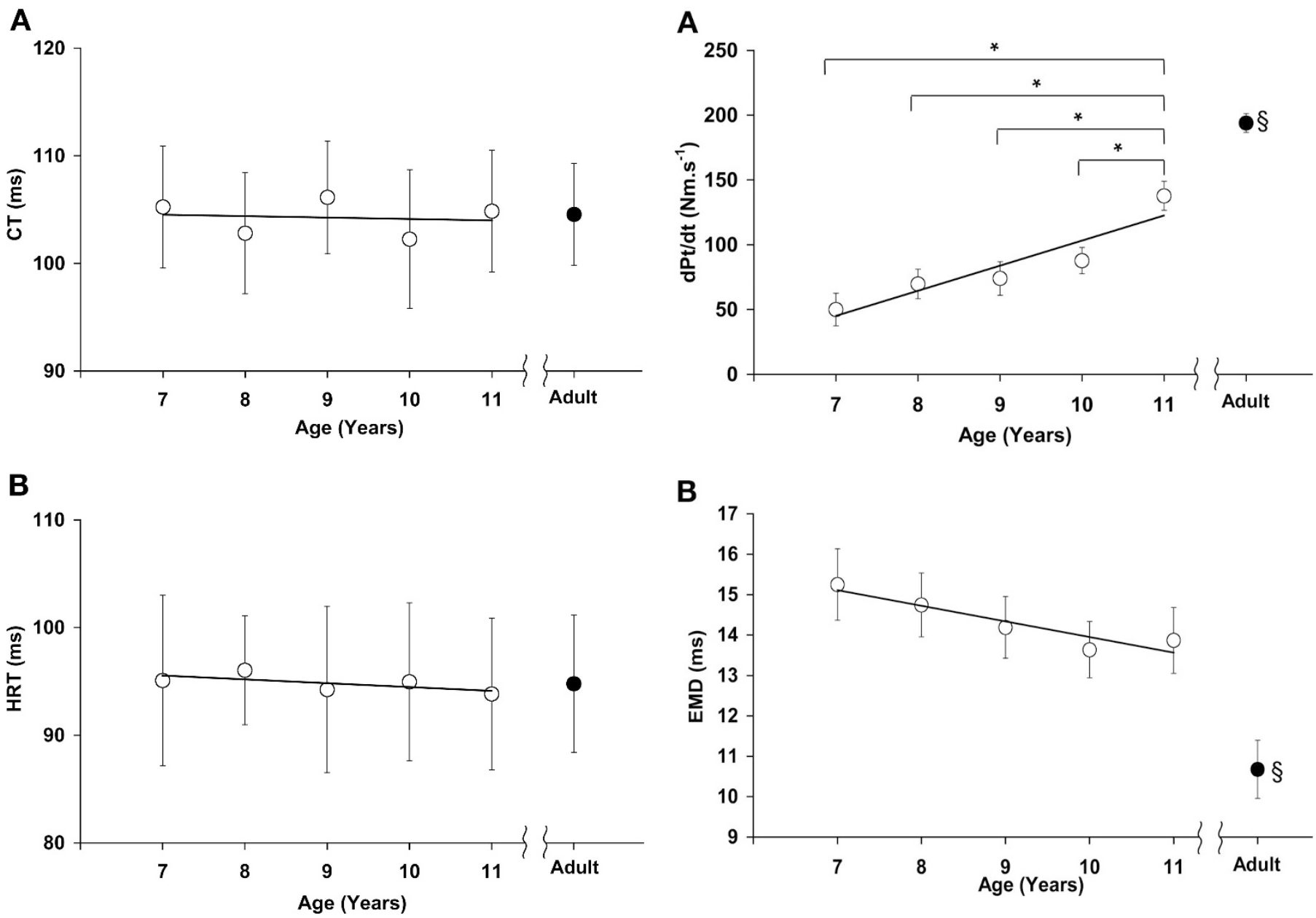

Figure 3. In $A$, contraction time (CT, ms) values for the different groups of prepubertal children $(O)$ and for adult subjects $(\bullet)$. In $B$, half relaxation time (HRT, ms) values for the different groups of prepubertal children and for adult subjects. Clearly, no significant differences and correlation were found for both parameters and mean data of children were already at adult values $(n=48 ; p$ $>0.05)$. Data are represented as mean $\pm \mathrm{SE}$.

Twitch peak torque and time course. The age-related increase in the maximal twitch torque, elicited by supramaximal stimulation of the posterior tibial nerve, indicates an improvement of the contractile properties with the age of the prepubertal children. This result also reflects an improvement in neuromuscular efficiency (torque to muscle activation ratio), which, if evaluated by the ratio between twitch peak torque and M-wave amplitude (17), will be obviously related to the age of the children because of the constancy of the M-wave with age. Significant increases in $\mathrm{Pt}$ values were already reported when comparing prepubertal to postpubertal children (1-4). The higher Pt values are classically considered to reflect different peripheral mechanisms which could accompany growth: (i) increase in muscle fibre diameter until growth is completed (18); (ii) increase in the number of sarcomeres with relation to muscle fibers size $(19,20)$; (iii) changes in the activity of myosin ATPase, which highly contributes to contractile characteristics, and which is higher for an adult muscle than for a child muscle (21). Because peak torque related to calf circumference increases with age, it can be proposed that for humans, ATPase activity also increases with the age of the child.

Figure 4. In $A$, relationship between the rate of torque development $(\mathrm{dPt} / \mathrm{dt}$, $\mathrm{Nm} \cdot \mathrm{s}^{-1}$ ) and the age of the prepubertal children (O); adult data are also given (O). In $B$, relationship between the electromechanical delay (EMD, ms) and the age of prepubertal children and for adult subjects. *Significant differences between prepubertal children of different age. §Significant differences between the adult subjects and each prepubertal child group from ANOVA $(n=48 ; p$ $<0.05)$. Data are represented as mean $\pm \mathrm{SE}$

However, the higher contractile properties does not seem to be caused by changes in myotypology because the myotypological profile is considered to be acquired at age 3 years (22). This can explain that the time-course characteristics, namely the contraction time and the half relaxation time, did not present significant differences with the age of the prepubertal children. Considering that the time course of a twitch elicited in vivo informs about the muscle fibre type distribution $(23,24)$, the triceps surae fibre type distribution seems to be the same for prepubertal children between 7 and 11 years. These results were also found when comparing CT and HRT values of the twitch of the triceps surae between prepubertal and postpubertal children (1-4).

Rate of torque development. Despite CT and HRT values did not change with age, some differences appeared in the twitch kinetics, because for the youngest children, the same contraction time was needed to reach a lower peak torque. These changes in twitch kinetics are well-illustrated by the increase in the $\mathrm{dPt} / \mathrm{dt}$ values with the age of the children. Studies on whole muscle (25) or isolated fibers (25-27) have 
demonstrated that the rate of torque development represents the kinetics of intracellular $\mathrm{Ca}^{2+}$ release. In vivo, those intracellular processes largely contribute to the increase in the rate of torque development and $\mathrm{dPt} / \mathrm{dt}$ is considered as a good indicator of contractile kinetics. Furthermore, some authors have suggested that this parameter is also dependent on the elastic charge time related to the stiffness of the muscle-tendon unit $(12,28,29)$. Thus, it can be proposed that during the growth of prepubertal children, the changes in contractile kinetics and/or in elasticity of the muscle-tendon unit are sufficiently important to be appreciated by the measurement of the rate of torque development.

Electromecanical delay. The measurement of the electromechanical delay is more often chosen to evaluate the contribution of the elastic components of the muscle-tendon unit. Many factors and structures are involved in an EMD evaluation like the propagation velocity of action potential along the muscle-fibers membrane and the time course of the excitationcontraction coupling processes (11,30-33). However, the time taken to stretch the muscle-tendon unit is considered to account for the essential part of an EMD value (11). The adult subjects tested in this study presented EMD values in the range of that described in the literature (between 9.5 and $18.77 \mathrm{~ms}$ ) (12-14). To our knowledge, EMD was never measured in children for the triceps surae muscle. Only Asai and Aoki (34) were interested to study EMD for elbow flexors in dynamic and static conditions and found longer EMD for the 6-year-old children than for adults. The higher EMD values found for prepubertal children and the age-dependent changes of this parameter give indications concerning an increase in musculotendinous stiffness in this range of age. In a previous article, we have already documented changes in musculo-tendinous stiffness by using a quick-release method (35). The present results indicate that a simple twitch analyzed in children can inform about contractile kinetics and musculo-tendinous stiffness.

\section{CONCLUSION}

The present study confirms, for prepubertal children, the increase in twitch peak torque with the age caused by growth processes. As when comparing prepubertal and postpubertal children, the time course characteristics of the twitch were not affected by the age. However, the increase in the rate of torque development and the decrease in electromechanical delay are indirect indicators of changes in contractile kinetics and in musculo-tendinous stiffness with the age of the prepubertal children. The present study gives reference values and age relationships for healthy children. Thanks to these reference values, the same type of twitch analysis may be undertaken in immobilized or injured children. This constitutes a simple test, noninvasive, painless, and nonfatiguing to assess changes in mechanical properties caused by disease or immobilization. Such an analysis in prepubertal children with osteonecrosis of the hip is now in progress.

Acknowledgments. The authors express their gratitude to the children who participated in this study, to the medical staff and notably to Pr. Pierre-Louis Doutrellot and Dr. Martine Verhaeghe from the University Hospital Center in Amiens.

\section{REFERENCES}

1. Belanger AY, McComas AJ 1989 Contractile properties of human skeletal muscle in childhood and adolescence. Eur J Appl Physiol Occup Physiol 58:563-567

2. Davies CT, White MJ, Young K 1983 Muscle function in children. Eur J Appl Physiol Occup Physiol 52:111-114

3. McComas AJ, Sica RE, Petito F 1973 Muscle strength in boys of different ages J Neurol Neurosurg Psychiatry 36:171-173

4. Pääsuke M, Ereline J, Gapeyeva H 2000 Twitch contraction properties of plantar flexor muscles in pre- and post-pubertal boys and men. Eur J Appl Physiol 82:459-464

5. Malina RM, Beunen G, Wellens R, Claessens A 1986 Skeletal maturity and body size of teenage Belgian track and field athletes. Ann Hum Biol 13:331-339

6. Kanehisa H, Yata H, Ikegawa S, Fukunaga T 1995 A cross-sectional study of the size and strength of the lower leg muscles during growth. Eur J Appl Physiol Occup Physiol 72:150-156

7. Davies CT 1985 Strength and mechanical properties of muscle in children and young adults. Scand J Sports Sci 7:11-15

8. Duchateau J, Hainaut K 1987 Electrical and mechanical changes in immobilized human muscle. J Appl Physiol 62:2168-2173

9. Duchateau J, Hainaut K 1988 Training effects of sub-maximal electrostimulation in a human muscle. Med Sci Sports Exerc 20:99-104

10. Scaglioni G, Narici MV, Maffiuletti NA, Pensini M, Martin A 2003 Effect of ageing on the electrical and mechanical properties of human soleus motor units activated by the H reflex and M wave. J Physiol 548:649-661

11. Cavanagh PR, Komi PV 1979 Electromechanical delay in human skeletal muscle under concentric and eccentric contractions. Eur J Appl Physiol Occup Physiol 42:159-163

12. Winter EM, Brookes FB 1991 Electromechanical response times and muscle elasticity in men and women. Eur J Appl Physiol Occup Physiol 63:124-128

13. Muro M, Nagata A 1985 The effects on electromechenical delay of muscle stretch of the human triceps surae. In: Winter DA, Norman RW, Wells RP, Hayes KC, Palta AE (eds) Biomechanics IX-A. Human Kinetics, Champaign, pp 86-90

14. Mora I, Quintero-Blondin S, Pérot C 2003 Electromechanical assessment of ankle stability. Eur J Appl Physiol 88:558-564

15. Tognella F, Mainar A, Vanhoutte C, Goubel F 1997 A mechanical device for studying mechanical properties of human muscles in vivo. J Biomech 30:1077-1080

16. Lambertz D, Goubel F, Pérot C 2002 A method to evaluate reflex excitability of the human ankle plantarflexors despite changes in maximal activation capacities. Exp Brain Res 143:89-99

17. Maffiuletti NA, Martin A, Babault N, Pensini M, Lucas B, Schieppati M 2001 Electrical and mechanical $\mathrm{H}(\max )$-to-M(max) ratio in power- and endurance-trained athletes. J Appl Physiol 90:3-9

18. Aherne W, Ayyar DR, Clarke PA, Walton JN 1971 Muscle fibre size in normal infants, children and adolescents. An autopsy study. J Neurol Sci 14:171-182

19. Bowden DH, Goyer RA 1960 The size of muscle fibers in infants and children. Arch Pathol 69:188-189

20. Mersch F, Stoboy H 1989 Strength training and muscle hypertrophy in children. In: Oseida, S, Carlsen KH (eds) Children and Exercise XIII. Human Kinetics, Champaign, pp $165-182$

21. Drachman DB, Johnston DM 1973 Development of a mammalian fast muscle: dynamic and biochemical properties correlated. J Physiol 234:29-42

22. Elder GC, Kakulas BA 1993 Histochemical and contractile property changes during human muscle development. Muscle Nerve 16:1246-1253

23. Rice CL, Cunningham DA, Taylor AW, Paterson DH 1988 Comparison of the histochemical and contractile properties of the human triceps surae. Eur J Appl Physiol Occup Physiol 58:165-170

24. Foehring RC, Sypert GW, Munson JB 1988 Relation of whole muscle contractile properties to source of innervation. Exp Neurol 101:366-373

25. Harridge SD, Bottinelli R, Canepari M, Pellegrino MA, Reggiani C, Esbjornsson M, Saltin B 1996 Whole-muscle and single-fibre contractile properties and myosin heavy chain isoforms in humans. Pflugers Arch 432:913-920

26. Ashley CC, Lea TJ, Mulligan IP, Palmer RE, Simnett SJ 1993 Activation and relaxation mechanisms in single muscle fibres. Adv Exp Med Biol 332:97-114

27. Patel JR, Diffee GM, Moss RL 1996 Myosin regulatory light chain modulates the $\mathrm{Ca} 2+$ dependence of the kinetics of tension development in skeletal muscle fibers. Biophys J 70:2333-2340

28. Viitasalo JT, Komi PV 1981 Interrelationships between electromyographic, mechanical, muscle structure and reflex time measurements in man. Acta Physiol Scand 111:97-103

29. Bell DG, Jacobs I 1986 Electro-mechanical response times and rate of force development in males and females. Med Sci Sports Exerc 18:31-36

30. Norman RW, Komi PV 1979 Electromechanical delay in skeletal muscle under normal movement conditions. Acta Physiol Scand 106:241-248

31. Hill AV 1949 The abrupt transition from rest to activity in muscle. Proc Roy Soc Lond B Biol Sci 136:399-420

32. Sandow A 1965 Excitation-contraction coupling in skeletal muscle. Pharmacol Rev $17: 265-320$

33. Alexander RM, Bennet-Clark HC 1977 Storage of elastic strain energy in muscle and other tissues. Nature 265:114-117

34. Asai H, Aoki J 1996 Force development of dynamic and static contractions in children and adults. Int J Sports Med 17:170-174

35. Lambertz D, Mora I, Grosset JF, Pérot C 2003 Evaluation of musculotendinous stiffness in prepubertal children and adults, taking into account muscle activity. J Appl Physiol 95:64-72 